NASA TECHNICAL MEMORANDUM

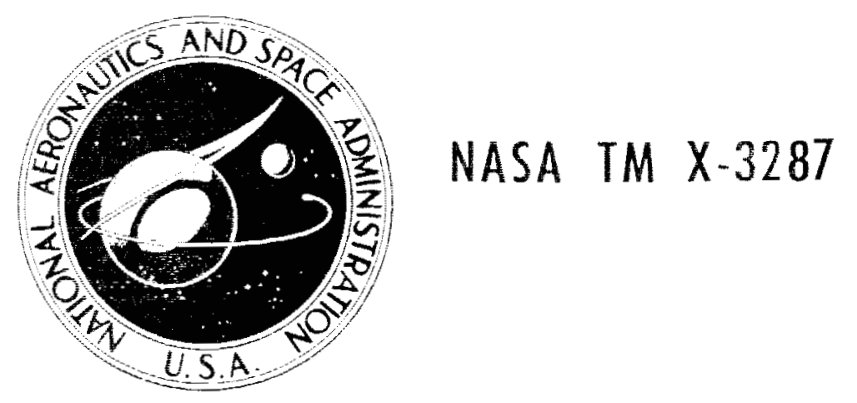

$$
\begin{aligned}
& \text { N } \\
& \Sigma \\
& \text { 芯 }
\end{aligned}
$$

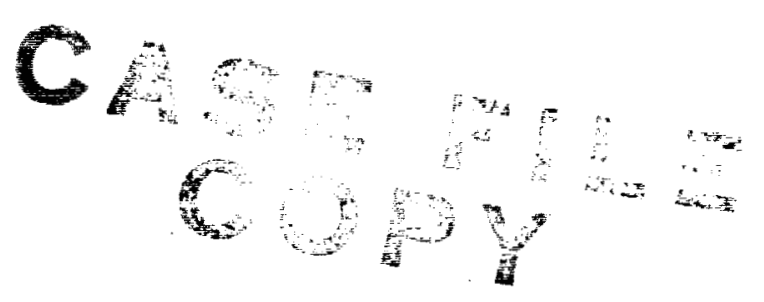

\title{
SYSTEM RELIABILITY ANALYSIS THROUGH CORONA TESTING
}

Vincent R. Lalli, Lawrence A. Mudler,

and Ennest A. Koutnik

Lewis Research Center

Cleveland, Obio 44135

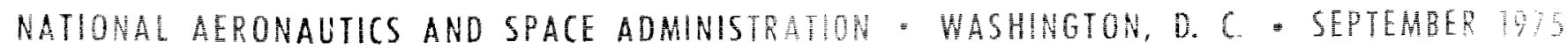




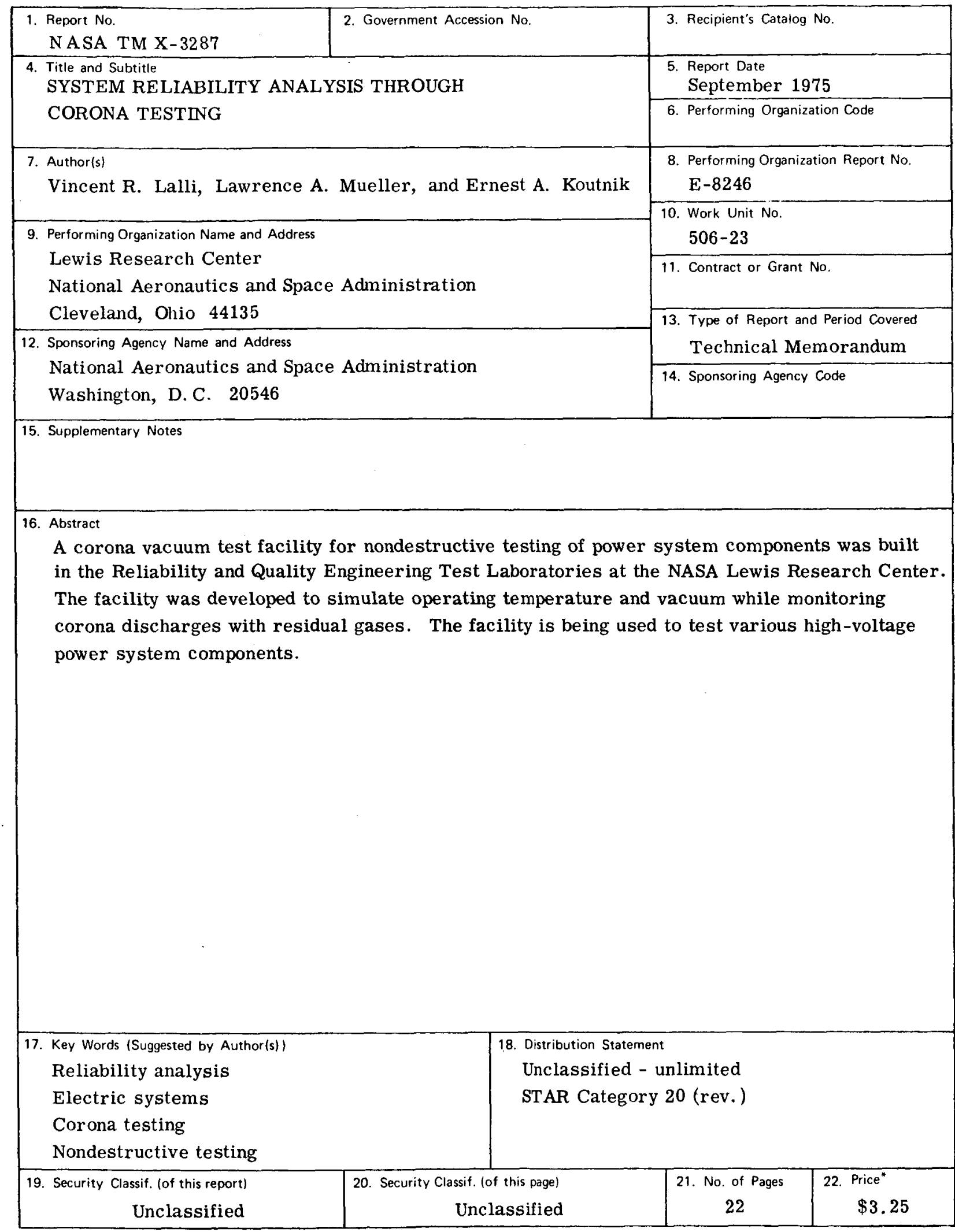

${ }^{*}$ For sale by the National Technical Information Service, Springfield, Virginia 22161 


\title{
SYSTEM RELIABILITY ANALYSIS THROUGH CORONA TESTING
}

\author{
by Vincent R. Lalli, Lawrence A. Mueller, and Ernest A. Koutnik* \\ Lewis Research Center
}

\section{SUMMARY}

A corona vacuum test facility for nondestructive testing of power system components is described. The facility was developed to simulate operating temperature and pressure while monitoring corona discharges with residual gases. The facility can create the following conditions, which simulate those that components of a space power system would see:

Temperature, ${ }^{\circ} \mathrm{C}$. . . . . . . . . . . . . . . . . -185 to 540

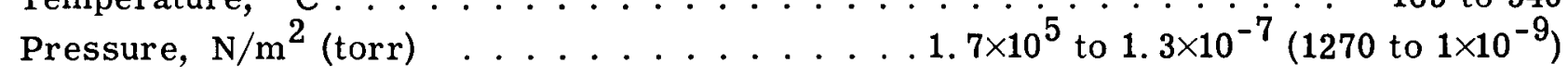
Corona discharge rate, discharges $/ \mathrm{min}$

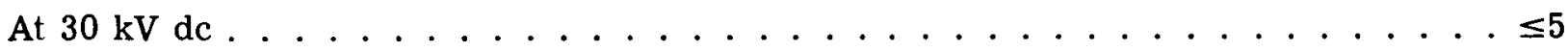

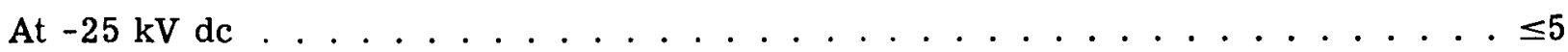

At $20 \mathrm{kV} \mathrm{ac}$. . . . . . . . . . . . . . . . . . . . . . . . $\leq 2$

Magnitude of discharges, $\mathrm{pC}$. . . . . . . . . . . . . . . . . . . $\leq 2$

Residual gas concentration, amu .................... . 1 to 500

Residual gas pressure, $\mathrm{N} / \mathrm{m}^{2}$ (torr) ....... $1.3 \times 10^{-5}$ to $1.3 \times 10^{-12}\left(10^{-7}\right.$ to $\left.10^{-14}\right)$

The facility is being used to test various high-voltage power system components. This report discusses tests on two of these components to explain how the facility is used. (The components tested were a Brayton cycle statorette model and a direct-current contacter developed for space nuclear systems.) The reliability of high-voltage power systems is related to leakage, corona, and evaporating gas parameters on a component level. As leakage and corona increase because of insulation deterioration, failure of the weak component becomes more and more probable. All power system components should be tested to determine that these parameters can be held to a specified minimum for extended periods to ensure a system reliability through corona testing.

* Presented at Power Electronics Specialists Conference sponsored by the Institute of Electrical and Electronic Engineers, Culver City, California, June 9-11, 1975. 


\section{INTRODUCTION}

A wide variety of energy conversion systems are being developed by NASA (refs. 1 and 2). Each of these systems converts a primary source of energy to electrical energy for distribution in more readily usable form. One of the major troublesome mechanisms by which electrical power sources deteriorate is excessive corona, which leads to permanent damage in the form of leakage current. Corona is a manifestation of ionization in an insulating system (refs. 3 and 4). Under many conditions corona is detrimental to insulation and consequently should be avoided in electrical power systems that are required to last a long time and perform with high reliability. Corona discharges may occur even at moderate voltages when the environmental conditions are appropriate, that is, when the effect of decreasing pressure in the altitude range from 45 to 75 kilometers is combined with temperature and material density changes. An insulating system is usually made up of several different materials in series from the voltage potential to its ground, for example, residual gases, ceramics, and plastics. Momentary breakdown in any one of the insulators in the series can cause deterioration of the insulation in the vinicity of the discharge site and can jeopardize the long life and high reliability of the electrical system. Even though the remaining insulation continues to function normally after the local discharge, some of the insulation near the discharge site may have been affected (erosion could remove material and metallizing could deposit thin films on the insulator surfaces) (refs. 5 to 12). If the corona continues for an extended period, leakage starts to rise, which indicates that the complete insulation system is in danger. To achieve long insulation life ( 2 to $5 \mathrm{yr}$ ) and improved reliability, it is necessary to reduce corona discharges to a minimum if not eliminate them entirely.

In the Reliability and Quality Engineering Test Laboratories at the NASA Lewis Research Center a facility has been built to measure corona characteristics of parts of electrical power systems under conditions likely to be encountered in the operating environment of the power system. The interface problems encountered with components from two specific test programs are described in this report. The components studied were (1) a reactor Brayton cycle space power system statorette, studied to determine corona threshold level (ref. 13) and selected because it exhibits the failure mechanism of erosion by corona, and (2) a nuclear space power system direct-current contactor, studied to determine and improve corona performance (ref. 14) and selected because it exhibits the failure mechanism of metallizing that deposits thin films on insulator surfaces by corona. This report also describes the corona vacuum test facility developed for nondestructive testing of power system components. 


\section{DESCRIPTION OF FACILITY AND TESTING PROCEDURES}

The presence of corona can be detected by various methods; a technique that uses a cathode-ray oscilloscope in connection with electronic transducers, filters, amplifiers, controls, instrumentation, and protective equipment is a very sensitive method. This method gives additional information on the time and phase relation between the corona and the applied periodic voltage. The development of this technique for laboratory use is discussed extensively in the literature (refs. 15 to 17). Extending the test appartus to include an environmental chamber with alternating-current voltages superimposed on direct-current voltages is a new development discussed in this report. Considerable difficulty was encountered when the test apparatus was extended to include a vacuum chamber (fig. 1), a temperature chamber, and a residual gas analyzer. Commercially purchased equipment intended to be used as part of this test apparatus did not meet the low-corona requirement. Fortunately, it was feasible to reduce the corona levels in the test apparatus to acceptable values by the use of guards, shields, and large-radii leads, so that voltages up to 30 kilovolts could be tested. In this manner the high-voltage displacement currents required by Maxwell's field equations, which could lead to internal arcing from high-voltage to low-voltage circuits (refs. 18 and 19), were reduced to minimum values. The remaining corona disturbances were lower in magnitude and the periods between occurrences were longer. Thus, long life systems can be achieved with desired reliabilities.

\section{Brayton Cycle Statorette Models}

Testing of the Brayton cycle statorettes (fig. 2) presented problems requiring the special facility features discussed in this section.

Three statorette models were prepared for measurements of corona threshold voltage in three gases over a three-decade pressure range. Cross-sectional diagrams of the three statorette models are shown in figure 3. Table I lists the statorette descriptions, sizes, and insulation systems. The corona threshold voltage $v_{c t}$ is given by

$$
v_{c t}=\frac{\epsilon_{1} V_{g}}{t_{1}} \sum_{n=1}^{j} \frac{t_{n}}{\epsilon_{n}}
$$

where

$\epsilon_{1}$ dielectric constant of gaseous insulator 
$\mathrm{V}_{\mathrm{g}} \quad$ breakdown voltage of gaseous insulator

$t_{1}$ thickness of gaseous insulator

n number of insulating material layers

$\mathrm{t}$ thickness of particular insulating material

$\epsilon \quad$ dielectric constant of particular insulation

The test gases selected were air, argon, helium, and mixtures of helium (He) and xenon (Xe) having molecular weights of 84, 40, and 20. These gases were chosen for the following reasons:

(1) An He-Xe mixture is the working fluid of the reactor Brayton cycle power system. (However, Paschen curves for He-Xe mixtures are not available to permit calculations.)

(2) Air and argon are used for ground testing.

(3) Helium, air, and argon permit comparison with calculated data.

Each statorette model was tested in a modified high-vacuum pumping station (fig. 2). The pumping system contained a liquid-nitrogen- and water-cooled baffle, a 25. 4centimeter (10-in.) $\left(0.25-\mathrm{m}^{3} / \mathrm{sec}\right)$ diffusion pump, a liquid-nitrogen-cooled trap on a 1. 0-cubic-meter-per-minute holding pump, and a 28.3-cubic-meter-per-minute central roughing system. The following modifications were necessary to convert this vacuum pumping station into a corona threshold test facility:

(1) Each O-ring-sealed surface was clamped to withstand a maximum test pressure of $1.69 \times 10^{5}$ newtons per square meter (1270 torr).

(2) A 1. 3-centimeter-(1/2-in. -) diameter high-voltage transmission line (of copper tubing) was run from the corona tester to the test specimen.

(3) The tubing from the corona tester to the vacuum chamber was shielded with 15. 2-centimeter (6-in.) galvanized pipe.

(4) The 1.3-centimeter (1/2-in.) tubing was supported with polystyrene standoffs.

(5) All directional changes were guarded with 2.5-centimeter (1-in.) corona balls.

(6) The vacuum feedthrough was guarded with 1.3 -centimeter-(1/2-in. -) radius cover rings.

The corona detector included the following modules installed in a chassis for rack mounting (see fig. 1):

(1) An oscilloscope module with a 7.6-centimeter-(3-in. -) diameter display tube, provision for flat or elliptical sweep traces, a 0 to $90^{\circ}$ phase selector switch, and front-panel controls for intensity, focus, and $\mathrm{x}$ - and $\mathrm{y}$-position

(2) A pulse amplifier module with a band pass from 20 to 50 kilohertz, alpha response characteristics, a seven-position input attenuator switch with steps of 10 decibels, and auxiliary output recepticals 
(3) An alternating-current kilovoltmeter module with four ranges ( 0 to 5,5 to 10 , 10 to 25 , and 25 to $50 \mathrm{kV} \pm 4$ percent of full scale), peak sensing but calibrated in root mean square for a pure sine wave

(4) A calibrator module with a front-panel output meter calibrated directly in picocoulombs, six output ranges $(0-5,5-10,10-50,50-100,100-500$, and 500$1000 \mathrm{pC}$ ), and an on-off output control allowing continuous variation from 0.1 to 1000 picocoulombs

A regulated power supply for the four modules was mounted in the chassis. Power could be supplied to the modules separately or together from supply lines carrying 105 to 125 volts at 50 to 60 hertz. The corona detector and modified vacuum pumping station exhibited no more than two discharges per minute with apparent magnitudes no greater than 1.0 picocoulomb at voltages up to 10 kilovolts of alternating current at 60 hertz. To measure the $V_{c t}$ each statorette was placed in the modified vacuum tank as shown in figure 3. The top and bottom conductors were brought out through two separate high-voltage feedthroughs, and the stainless steel block which contained the statorette model was grounded to the vacuum tank and corona detector. The tank was closed, evacuated, and then filled with the desired test gas to a pressure of $1.7 \times 10^{5}$ newtons per square meter (1270 torr). The $\mathrm{V}_{\text {ct }}$ was measured three times at each pressure. As shown in the following table, the three measurements differed in the manner in which the corona tester was connected to the test specimen:

\begin{tabular}{|c|c|c|}
\hline $\begin{array}{c}\text { Measure- } \\
\text { ment }\end{array}$ & $\begin{array}{c}\text { Top } \\
\text { conductor }\end{array}$ & $\begin{array}{c}\text { Bottom } \\
\text { conductor }\end{array}$ \\
\hline 1 & High voltage & Grounded \\
2 & $\begin{array}{c}\text { Floating } \\
\text { High voltage }\end{array}$ & $\begin{array}{c}\text { Floating } \\
\text { Floltage }\end{array}$ \\
\hline
\end{tabular}

The tank was pumped down in steps to pressures of $1.4 \times 10^{5}, 1.0 \times 10^{5}, 6.8 \times 10^{4}$, $3.4 \times 10^{4}$, and $6.8 \times 10^{3}$ newtons per square meter (1016, 762, 508, 254, and 51 torr). The same $V_{c t}$ measurements were made at each pressure setting. These $V_{c t}$ measurements were also obtained for mixtures of the He and Xe of lower molecular weight as follows:

(1) The tank was evacuated as before and then filled with ( $\mathrm{He}-\mathrm{Xe}$ ) 84 to a predetermined pressure less than $1.7 \times 10^{5}$ newtons per square meter (1270 torr).

(2) Pure helium was added to bring the pressure up to $1.7 \times 10^{5}$ newtons per square meter (1270 torr).

(3) Samples were taken and tested to verify that the correct molecular weight had been obtained. 
Testing of the nuclear power system direct-current contactor presented problems requiring the special facility features discussed in this section. Two contactors were prepared for corona voltage and current leakage measurements in vacuum with controlled and monitored residual gases over a three-decade pressure range. Cross sections of the two direct-current contactor models are shown in figures 4 and 5 . Each contactor is made up of two main mechanisms: an actuator and an interrupter. When the closing coil is energized, the upper and lower contacts close with wiping action. When the trip coil is energized, the armature is released from the closed position, and the contacts are forced open by springs in milliseconds. The residual gases around the component being tested were monitored. These gases were the result of initial pumpdown and the backfill dry nitrogen used for pressure control.

Each model of the direct-current contactor was tested in a modified vacuum pumping station as shown in figure 1. The vacuum pumping station was modified as follows:

(1) High-voltage transmission lines 1.3 centimeters ( $1 / 2$ in.) in diameter in copper tubing connected the corona tester to the chamber feedthrough. Vented stainless steel was used from the chamber feedthrough to the test specimen.

(2) Steps (3) to (6) of the modification procedure given in the previous section were repeated.

The pumping system includes a bulk titanium sublimation pump $\left(100 \mathrm{~m}^{3} / \mathrm{sec}\right)$, a triode ion pump $\left(1.2 \mathrm{~m}^{3} / \mathrm{sec}\right)$, a liquid-nitrogen cold baffle for cryogenic pumping $\left(8\left(\mathrm{~m}^{3} / \mathrm{sec}\right) /\right.$ $\left.\mathrm{m}^{2}\right)$, a molecular turbopump $\left(0.26 \mathrm{~m}^{3} / \mathrm{sec}\right)$, and a water-baffle molecular-sieve central roughing system $\left(28.3 \mathrm{~m}^{3} / \mathrm{min}\right)$. The cold baffle is also used as an oven heat sink. The chamber oven and test components are bakable to $200^{\circ} \mathrm{C}$. The internal shroud is $1 \mathrm{me}-$ ter in diameter and 1.80 meters long.

The corona detector used was the same one described in the previous section (fig. 1), but it was used with the larger chamber. An oven of special design was built to fit the vacuum chamber and also to accommodate the test components. It has a temperature range to $815^{\circ} \mathrm{C}\left(1500^{\circ} \mathrm{F}\right)$. The nominal dimensions are as follows: diameter, 51.3 centimeters ( 20.2 in.), and length, 98.3 centimeters ( 38.7 in.). Twenty-four quartz lamps are equally spaced around the circumference. They are wired in three banks of eight lamps each. This arrangement provides flexibility to ensure uniform heating of the test component. If a lamp were to fail during a test, the voltage on that particular bank could be increased.

The oven material is type 304 stainless steel. Alumina and boron nitride are used at insulating points. Two vacuum gages are mounted on the end baffle of the oven to monitor the pressure as close as possible to the test component. Seventeen thermocouples are installed outside or inside the oven at discrete points to monitor the temperatures. Test data showed the thermal profiles at these locations to be $\pm 30^{\circ} \mathrm{C}$ inside and 
$\pm 50^{\circ} \mathrm{C}$ outside. A thermocouple mounted on the test component was used as the control thermocouple. This design was able to control component temperature within \pm 5 percent.

For the corona tests, only the lower half of the direct-current contactor assembly (interrupter section) was used. This section includes all parts which are at high voltage in normal operation. The high-temperature mechanism which moves the solenoid armature was not used because the design had previously been proven and the main concern was the static condition of the open contacts.

The test component was mounted in a horizontal position in the oven installed inside the vacuum chamber. The high voltage was brought in from the corona test set through a bushing and lead which were designed to be corona free. The plus direct-current voltage was connected to the lower (fixed) contact. The upper (movable) contact and the outer nickel shell were grounded. The power for the quartz lamps to provide the heat was controlled by setting the controller, and the input rate was regulated by adjusting the voltage applied. Pressure was controlled by admitting dry nitrogen to the vacuum system and manipulating the vacuum pumps.

Residual gases were monitored by using a quadrupole mass spectrometer (QMS) (refs. 20 to 22). The QMS probe was attached directly to the vacuum chamber. The probe was functional only when the chamber pressure was lower than $1.8 \times 10^{-4}$ newton per square meter $\left(1 \times 10^{-6}\right.$ torr $)$. The ionizing, filtering, and detection of residual gases was accomplished in the probe, which was controlled by a small, rack-mounted electronic package. Spectral display was accomplished in real time at a fast rate on an oscilloscope or at a much slower rate on a strip-chart recorder. A parallel approach to the manual methods consists of using an analog-to-digital (A-D) computer interface and necessary computer hardware and software to process and display the spectral data. The computing equipment used for gas analysis is a variable factor depending on the gases to be observed. In most cases a time-shared 16-bit minicomputer with A-D and D-A cards and an expandable in-frame memory is sufficient.

The testing procedure used can be summarized as follows:

(1) The entire system, including the corona test set, was checked out with the contactor out of the oven by baking out the system and determining if corona was present. The temperature was raised to $540^{\circ} \mathrm{C}$, the same value as used for the later testing, to assure performance of the oven and other parts at this temperature.

(2) The contactor was installed and the lower (positive) terminal was connected to the high-voltage lead, while the upper (negative) terminal and case were grounded. The system was evacuated and baked out to get the contactor into the proper operating condition.

(3) The effects of temperature on corona threshold voltage were then determined by holding the chamber vacuum at constant pressure while the temperature varied from $20^{\circ}$ to $540^{\circ} \mathrm{C}$ in discrete steps. 
(4) The following data were recorded for each test point:

(a) Leakage current at 1000 volts direct current to determine the insulation resistance

(b) Corona threshold voltage and leakage current for positive test voltage

(c) Chamber pressure

(d) Contactor temperature

(5) Voltage was increased in 2.0-kilovolt steps until 20 kilovolts was reached (twice the rating of the contactor). Cor ona readings in picocoulombs and leakage current were recorded. The pressure in the chamber during the runs was in the range $1.3 \times 10^{-5}$ to 1. $3 \times 10^{-6}$ newton per square meter $\left(10^{-7}\right.$ to $10^{-8}$ torr $)$.

\section{RESULTS AND DISCUSSION}

The magnitude of corona is usually expressed in picocoulombs, the unit of charge. If corona is initiated in the residual gases surrounding a particular point, ionized regions are formed. These regions contain a plasma with positive and negative particles with sheaths on each boundary. A corresponding number of charge carriers are transferred in the ionized region between the capacitances in the circuit. The magnitude of corona measured at the detector is a function of where the ionized region occurs in the test specimen and its relative coupling capacitance. In order to determine the magnitude of corona in coulombs from a measured oscilloscope trace, it is necessary to calibrate the detector sensitivity to corona pulses. For such a calibration, a pulse generator is required to introduce a simulated corona pulse in the test circuit. The magnitude of the calibration pulse is varied while observing the detector oscilloscope screen until the calibration pulse is equal in magnitude to that of the pulse produced by the corona signal. The magnitude is read directly on a picocoulomb meter. The relation between the amount of insulation damage and the magnitude of corona depends on the test circuit configuration and the primary failure mode, as the statorette and direct-current contactor examples illustrate.

\section{Brayton Cycle Statorette Models}

The $\mathrm{V}_{\mathrm{ct}}$ test results for the three statorettes are shown in figure 6 . The experimental curves for air, argon, and helium show the same general trends as the theoretically calculated curves, namely,

(1) The $V_{c t}$ increases with pressure in the range $6.8 \times 10^{3}$ to $1.7 \times 10^{5}$ newtons per square meter ( 51 to 1270 torr). 
(2) Of the three gases shown in figure 6 air exhibits the highest corona threshold voltage, helium the lowest voltage, and argon an intermediate voltage.

(3) The effect of pressure is most pronounced for air and least for helium.

Analysis of the test data shows that the $\mathrm{V}_{\mathrm{ct}}$ for the He-Xe mixture is closer to that of argon than to that of air or helium. This suggests that, since Paschen curves for He-Xe are not available for calculations, a fair approximation can be obtained by using the Paschen curve for argon, if the He-Xe mixture has a molecular weight between 20 and 40 . The variation with molecular weight is an indication of the energy variation of the electron-atom collision cross sections and the lifetimes of the excited species in the plasma, which are ultimately determined by the electronic (internal) structure of the residual gas atoms. Consequently, the ability of the electrons to diffuse through the gas as a function of the applied voltage will determine the $V_{c t}$ values (refs. 23 and 24). Test data indicate that, as the molecular weight of the reisdual gas decreases, the $V_{c t}$ decreases until the limiting helium performance is reached. The comparison is representative of all the curves and shows that good general agreement exists between calculated and measured results.

\section{Nuclear Power System Direct-Current Contactor}

The corona voltage and leakage current test results for the two direct-current contactor models are shown in table II. The original configuration of the direct-current contactor (fig. 4) that was tested for its operational characteristics was also tested for its corona threshold and breakdown voltages. As shown in table II (a), the corona at 10 kilovolts was greater than 100 picocoulombs, and the leakage current at 10 kilovolts was greater than 300 milliamperes at $540^{\circ} \mathrm{C}$. Because of these high values design changes were made in the interrupter section of the contactor (see fig. 5) to increase the corona threshold voltage and decrease the leakage current.

The value of corona level is acceptable for the configuration of figure 5 up to 20 kilovolts (twice its rated voltage) at $540^{\circ} \mathrm{C}$. At 10 kilovolts the value of the leakage current for this configuration is acceptable, but at 20 kilovolts the value is somewhat high. Since the contactor was designed for 10 kilovolts, it amply meets the specification. Since the level of corona at 20 kilovolts is very low, the contactor has a 100-percent safety factor (when operating at $10 \mathrm{kV}$ ) to handle any transient voltage spikes up to 20 kilovolts, even at $540^{\circ} \mathrm{C}$.

If the operating temperature were reduced to $430^{\circ} \mathrm{C}$, the contactor could operate at twice its rating $(20 \mathrm{kV})$, since the leakage current was very low $(0.032 \mathrm{~mA})$ at this temperature.

The slight increase in both corona and leakage current with increasing temperature can be attributed to (1) the reduction in tension produced by the Inconel pressure springs; (2) outgassing of the materials; and (3) increasing molecular activity, which makes 
thermally generated electrons more readily available; all of which decrease the resistivity of the exposed materials (refs. 23 and 28).

The composition of the residual gases in these tests was largely uncontrolled. The gas composition during corona testing (configuration of fig. 5) was monitored to permit evaluation of the contactor in an environment which closely matched that used for operational testing (configuration of fig. 4). The test gas for the configuration of figure 4 represented that expected in a normal vacuum system. Pure nitrogen gas (99. 99 percent pure) was used to adjust the magnitude of the vacuum between tests. Although 99. 99-percent-pure dry nitrogen is bled into this corona testing apparatus, it was not unusual to detect only about 50 percent nitrogen or less in the vacuum chamber. The other 50 percent consisted of residual gases, which could affect the corona properties. The ion gage on the vacuum chamber can monitor total pressure but cannot indicate a small water leak or a high background of helium during the corona test. Various kinds of residual gases with excessive partial pressure levels during corona measurements can affect the electrical performance in a complicated manner. Table III shows the percentage composition of the residual gases for the test results given in table II. No new gases were introduced, and the partial pressures for the configuration of figure 4 were within 3 percent of those for the configuration of figure 5 . The principal cause for high corona and leakage at lower voltages and temperatures for the configuration of figure 4 was the line of sight metal film deposition occurring on the alumina insulators.

During the course of testing the configuration of figure 5 , an arc-over occurred across the open contacts at 19 kilovolts and $95^{\circ} \mathrm{C}$. Also, at $205^{\circ} \mathrm{C}$ an arc-over occurred at 19 and 20 kilovolts. Reference 27 notes that if the electrode gap is continually sparking over, even in vacuum only, the breakdown voltage increases until it reaches a plateau. Evidently, when arc-over occurred in this experiment, it conditioned the contacts since it never occurred after that, even at the much higher tempeatures. Slivkov (ref. 28) found that, for heated nickel electrodes at temperatures up to $800^{\circ} \mathrm{C}$, the breakdown strength coincided within 5 percent with measurements obtained at ambient temperature. The fact that no arc-over occurred at the $540^{\circ} \mathrm{C}$ test temperature of this experiment indicates that breakdown voltage is not significantly influenced by temperature.

Differences in pressure at approximately $1.3 \times 10^{-4}$ newton per square meter $\left(10^{-6}\right.$ torr) and lower did not affect the corona and leakage level measurements.

The contactor was also tested with reversed polarity. The significant increase in corona that resulted suggests that the contractor would have to be derated to be used with reverse polarity. Therefore, for maximum service life the contactor should be wired with the plus direct-current voltage applied to the lower (fixed) contact and the upper (movable) contact grounded. Upon completion of all the testing the contactor was disassembled and inspected; minor deterioration of components was observed.

Based on these results, it may be concluded that the contactor design shown in fig- 
ure 5 is satisfactory and meets its design specifications. The reliability of high-voltage power system components is related to leakage, corona, and evaporating gas parameters on a component level. As leakage and corona increase because of insulation deterioration, failure of the weak component becomes more and more probable. Power system components which have been optimized for corona and leakage performance can achieve long life and ensure a successful mission even though mean-time-between-failure estimates equal to or greater than the mission time for the power system cannot be exhibited by the small number of units built.

\section{CONCLUDING REMARKS}

Success in making corona measurements and using the results to improve reliability of power systems requires knowledge about the nature of corona electrical stresses and their effects on material strengths and performance of the electrical equipment and test apparatus for environmental simulation and measurements. The technique has been to use oscillographic methods of detection and to reduce corona streamers from the high-voltage circuits by using small-diameter conventional components with large-radius shielding. In this manner the insulating materials are protected from the deteriorating effects of corona impingements, and the useful life is greatly extended. Corona tests and measurements are used in research on power system components, in development of insulating systems, and in product assurance of power systems. The economical benefits resulting from corona testing have been important.

Corona threshold voltages obtained from statorette tests with various gas-solid dielectric systems and comparison with calculated data support the following conclusions:

(1) Of the gases tested, air gives the highest corona threshold voltage and helium the lowest. Argon and mixtures of helium and xenon are intermediate.

(2) Increasing the gas pressure increases the corona threshold voltage.

(3) Corona threshold voltage for an armature winding can be calculated by using Paschen curves for a uniform field. The results of the calculations give a good approximation to the observed values of corona threshold voltage.

(4) Paschen curves for argon can be used to calculate the corona threshold voltage for mixtures of helium and xenon for which Paschen curves are not available. The resultant approximation is most accurate for helium-xenon mixtures of molecular weight between 20 and 40 .

In addition, theory indicates that to increase the corona threshold voltage the following possibilities exist:

(1) Use a gas of higher breakdown strength

(2) Increase the effective insulation thickness by either increasing the actual insulation thicknesses $t_{2}, t_{3}, \ldots, t_{n}$ or by decreasing the dielectric constants $\epsilon_{2}, \epsilon_{3}, \ldots, \epsilon_{n}$. 
(3) Eliminate voids by filling them with a dielectric material.

(4) Eliminate the voltage stress across a gaseous gap by providing a conductive path across the gap.

A direct-current contactor $(10 \mathrm{kV}, 10 \mathrm{~A})$ was built for operation at $540^{\circ} \mathrm{C}$ and at a pressure of $1.3 \times 10^{-4}$ newton per square meter $\left(10^{-6}\right.$ tor $\left.\mathrm{r}\right)$ or lower. The contactor was tested at 10 kilovolts with a 100-percent margin on voltage in order to show tolerance of transient voltage spikes up to 20 kilovolts. When the operating temperature was reduced to $430^{\circ} \mathrm{C}$, the contactor operated successfully at twice its rating, or 20 kilovolts.

Testing in the corona vacuum facility of this type has defined several component problem areas that need to be considered in the design of direct-current contactors intended for long life missions:

(1) Maximum venting of the inner and outer ceramic insulators is required. This could be accomplished by inserting holes in all inner insulators and also by allowing ample spacing between the inner and outer insulators.

(2) Metallizing is required on the interface surfaces of all the ceramic insulators. This would provide maximum contact between the dielectric and the metallic conducting rings and would eliminate the possibility of any high-voltage gradients in these areas.

(3) Pressure springs on the assembly are required to maintain pressure on all the interfaces between the ceramic insulators and the metal conducting rings at the operating temperature.

(4) All parts that are at a positive potential should have round edges and smooth surfaces.

(5) A fast actuating mechanism that could operate at the high temperatures could be achieved through use of selected materials for the closing and trip coils, the magnets, the armature, and the springs.

Based on these results, it may be concluded that corona vacuum testing under simulated environmental conditions is worth the time and expense necessary to undertake such testing on a component level. The reliability of high-voltage power system components is related to leakage, corona, and evaporating gas parameters on a component level. As leakage and corona increase because of insulation deterioration, failure of the weak component becomes more and more probable. Power system components which have been optimized for corona and leakage performance can achieve long life and ensure system reliability through corona testing.

Lewis Research Center,

National Aeronautics and Space Administration, Cleveland, Ohio, July 2, 1975, 506-23. 


\section{REFERENCES}

1. Svernlicht, B., et al.: Space Power and Electric Propulsion. Vol. I, NASA, Technical Regional Aid Center, 1972.

2. Study of Aircraft Electrical Power Systems. (AIR-72-8414, AiResearch Manufacturing Co.; NAS3-14367.), NASA CR-120939, 1972.

3. Heinrich, O. S.: Corona Measuring Techniques and Their Use in Insulation System Evaluation. TB 66 TI, James G. Biddle Co., 1964.

4. Liao, T. W.; and Kresge, J. S.: Detection of Corona in Oil at Very High Voltages. AIEE Trans., vol. 73, pt. 3B, Dec. 1954, pp. 1389-1395.

5. Dunbar, William G.: Cor ona Onset Voltage of Insulated and Bare Electrodes in Rarefied Air and Other Gases. D2-84141-1, Boeing Co. (AFAPL-TR-65-122; $\mathrm{AD}-483820), 1966$.

6. Mason, J. H.; and Garton, C. G.: Insulation for Small Transformers, Guide to Design and Testing. Publ. L/T381, British Electrical and Allied Industries Research Assoc., 1959.

7. Kind, Dieter; and Konig, Dieter: AC Breakdown of Epoxy Resins by Partial Discharges in Voids. IEEE Trans. Electrical Insulation, vol. EI-3, no. 2, May 1968, pp. $40-46$.

8. Halleck, M. C.: Calculation of Corona-Starting Voltage in Air-Solid Dielectric Systems. AIEE Trans. Power Apparatus and Systems, vol. 75, pt. 3, Apr. 1956, pp. 211-216.

9. Olyphant, Murray, Jr.: Corona and Treeing Breakdown of Insulation - Progress and Problems. Insulation, vol. 9, no. 2, Feb. 1963, pp. 35-40.

10. Rhudy, R. G.; and Mazanek, H. E.: Accelerated Voltage - Endurance Tests. AIEE Trans. Power Apparatus and Systems, vol. 79, pt. 3, Aug. 1960, pp. 576580 .

11. McMahon, Eugene J.: The Chemistry of Corona Degradation of Organic Insulating Materials in High-Voltage Fields and Under Mechanical Strain. IEEE Trans.

Electrical Insulation, vol. EI-3, no. 1, Feb. 1968, pp. 3-10.

12. Kreuger, F. H.: Determination of the Internal Discharge Resistance of Dielectric Materials. IEEE Trans. Electrical Insulation, vol. EI-3, no. 4, Nov. 1968, pp. $106-114$.

13. Bollenbacher, Gary; and Kempke, Erwin E., Jr.: Corona Inception Voltage in Statorettes with Various Gas-Solid Dielectric Systems. NASA TM X-2474, 1972. 
14. Mueller, Lawrence A.; Medwid, David W. ; Koutnik, Ernest A.; and Powell, A. H.: Design, Performance, and Evaluation of a Direct-Current Contactor for Space Nuclear Electrical Systems. NASA TN D-6699, 1972.

15. Hagenyuth, J. H.; and Liao, T. W.: Impulse Corona Detection, Measurement of Intensity and Damage Produced. AIEE Trans., vol. 71, pt. 3, Jan. 1952, pp. 461465.

16. Hopkins, R. J.; Walters, T. R.; and Scoville, M. E.: Development of Corona Measurements and Their Relationship to the Dielectric Strength of Capacitors. AIEE Trans., vol. 70, pt. 2, 1951, pp. 1643-1651.

17. Nye, J. R.; and Wilson, W. R.: Physical Concepts of Corona in Capacitors. AIEE Trans., vol. 72, pt. 3, Aug. 1953, pp. 781-787.

18. Lalli, Vincent R.: Electrical Stress Analysis of a Microthruster Power Conditioner. NASA TM X-1686, 1968.

19. Lalli, V. R.; and Vargo, D. J.: Aerospace Reliability Applied to Biomedicine. IEEE Trans. Industrial Electronics and Control Instrumentation, vol. IECI-19, no. 2, May 1972, pp. 40-49.

20. Hultzman, William W.: Characteristics and Performance of Several Mass Spectrometer Residual Gas Analyzers. NASA TN D-7554, 1974.

21. Babst, R. W.: A Computer Program for Qualitative and Quantitative Analysis of Low-Resolution Mass Spectra. DIRS-02501, NASA Goddard Space Flight Center, 1971.

22. Trombka, J. I. ; and Schmadebeck, R. L.: A Numerical Least-Square Method for Resolving Complex Pulse Height Spectra. NASA SP-3044, 1968.

23. Llewellyn-Jones, F.: The Glow Discharge and Introduction to Plasma Physics. Methuen and Co., Ltd., London, John Wiley \& Sons, New York, 1966, pp. 136-152.

24. Cobine, James D.: Gaseous Conductors, Theory and Engineering Applications. Dover Publ., Inc., 1941.

25. Kueser, P. E.; Toth, J. W.; and McRae, R. C.: Bore Seal Technology Topical Report. (WAED-64, 5HE, Westinghouse Electric Corp.; NAS3-4162.), NASA CR-54093, 1964.

26. Spangenburg, Karl R.: Vacuum Tubes. McGraw-Hill Book Co., Inc., 1948.

27. Hawley, R.: Vacuum as an Insulator. Vacuum, vol. 19, no. 4, Sept. 1960, pp. 310-318.

28. Slivkov, I. N.: Mechanism for Electrical Discharge in Vacuum. Soviet Phys. Tech. Phys., vol. 2, no. 9, Sept. 1957, pp. 1928-1934. 


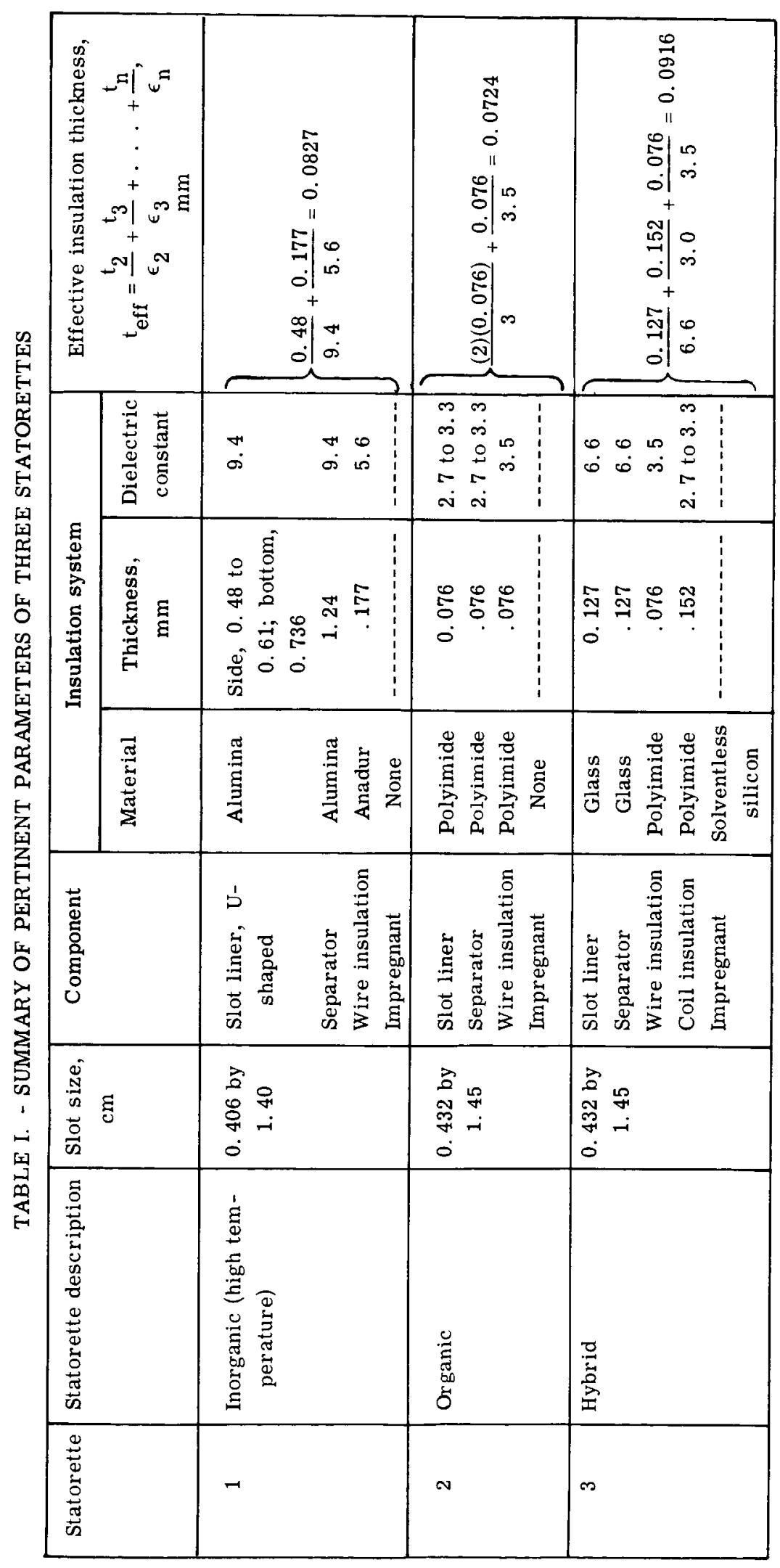



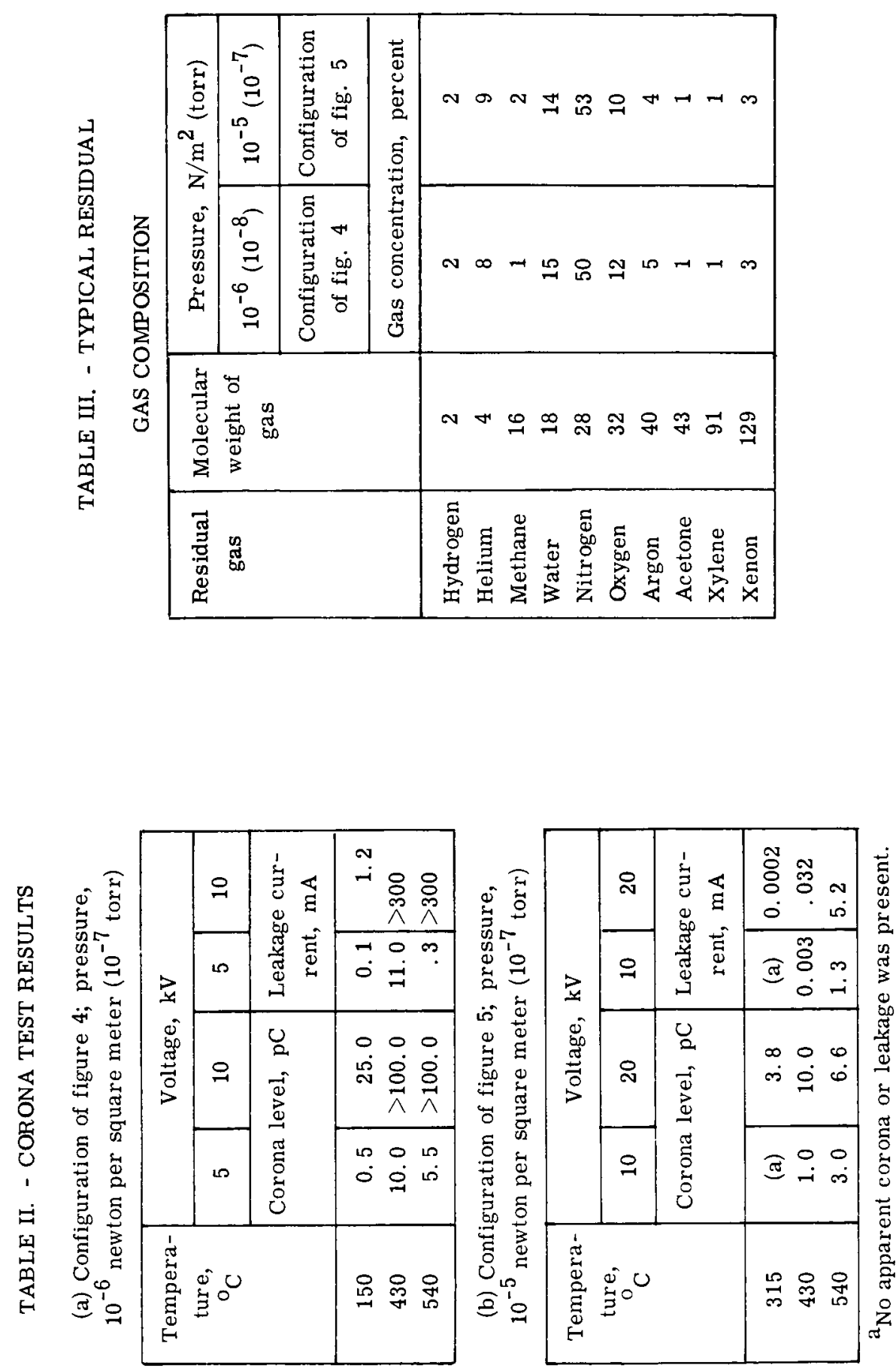


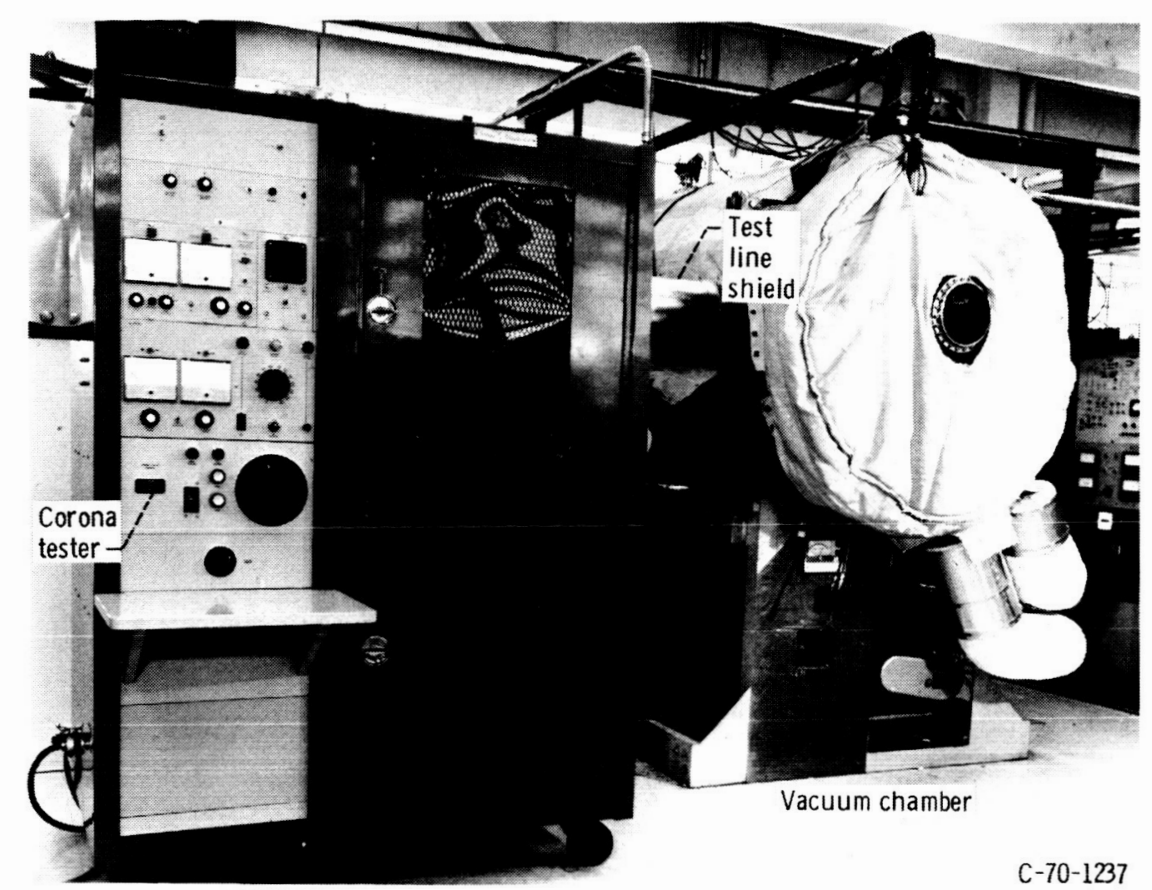

Figure 1. - Direct-current contactor corona test facility.

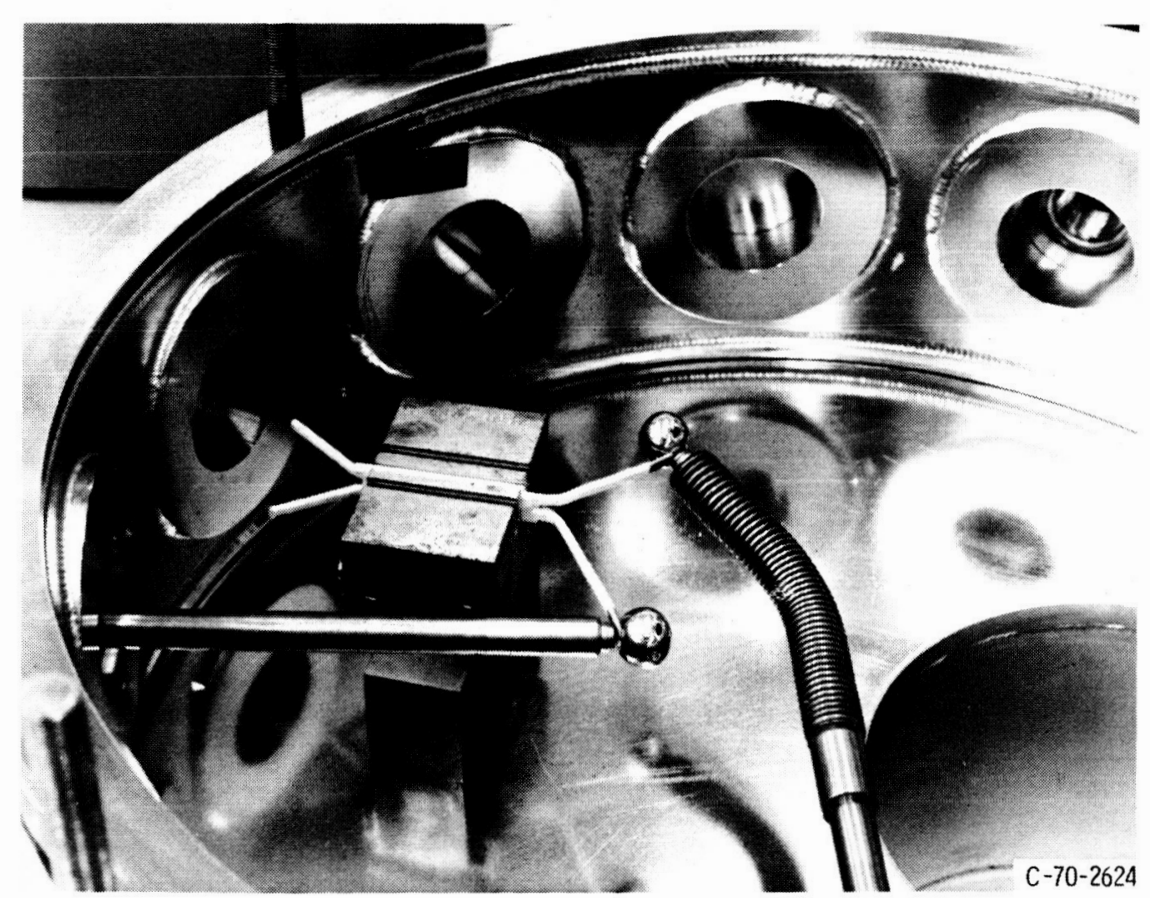

Figure 2 - Statorette 1 installed in modified vacuum tank. 


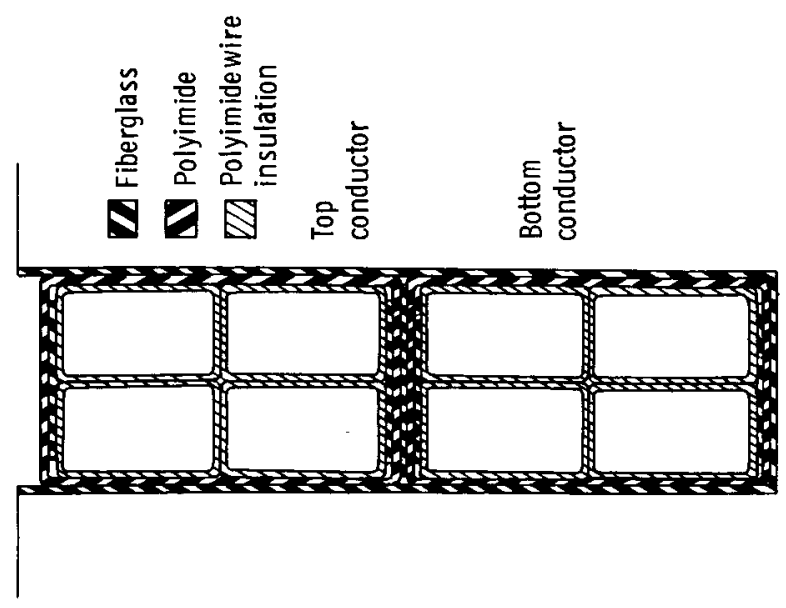

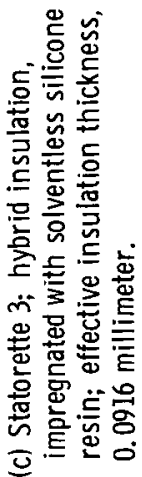

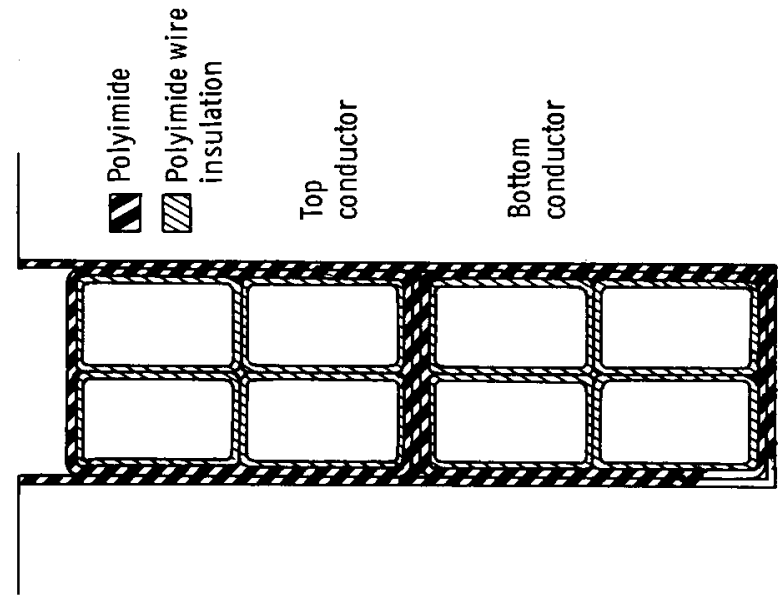

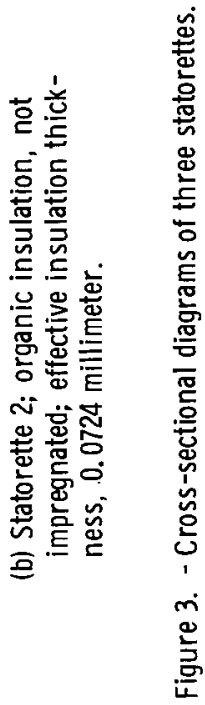

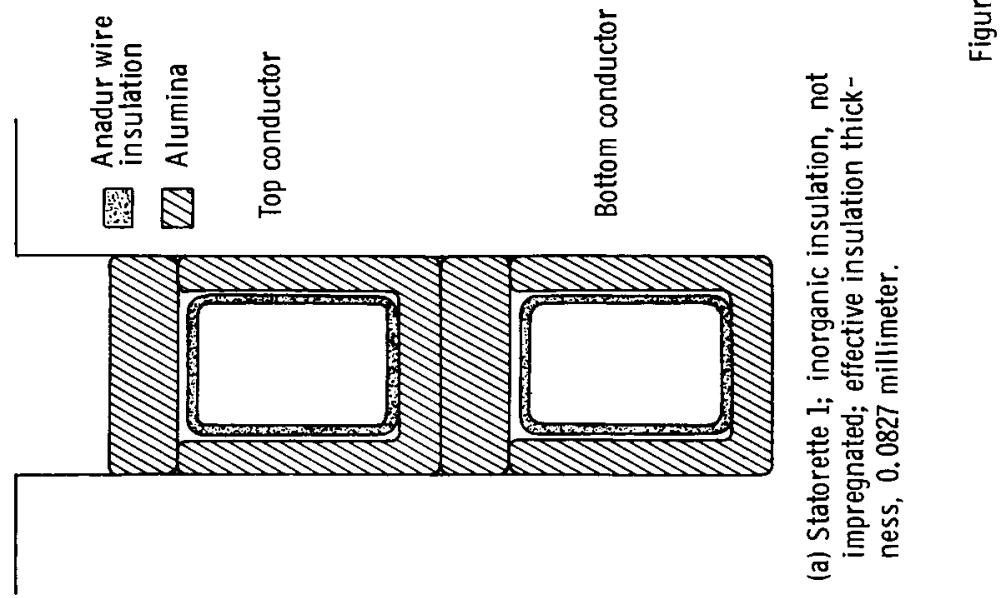




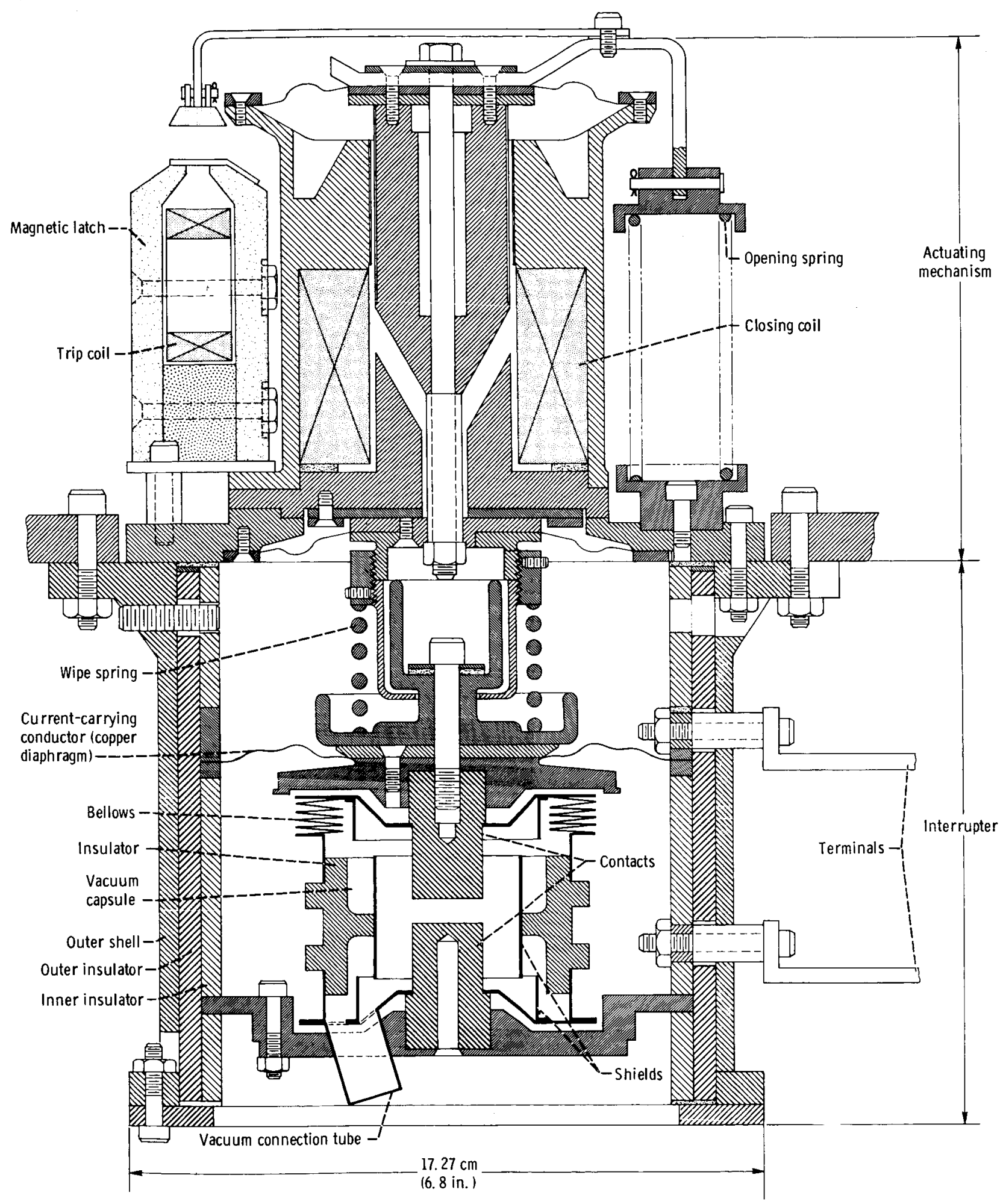

Figure 4. - Cross section of direct-current contactor for operational testing. 


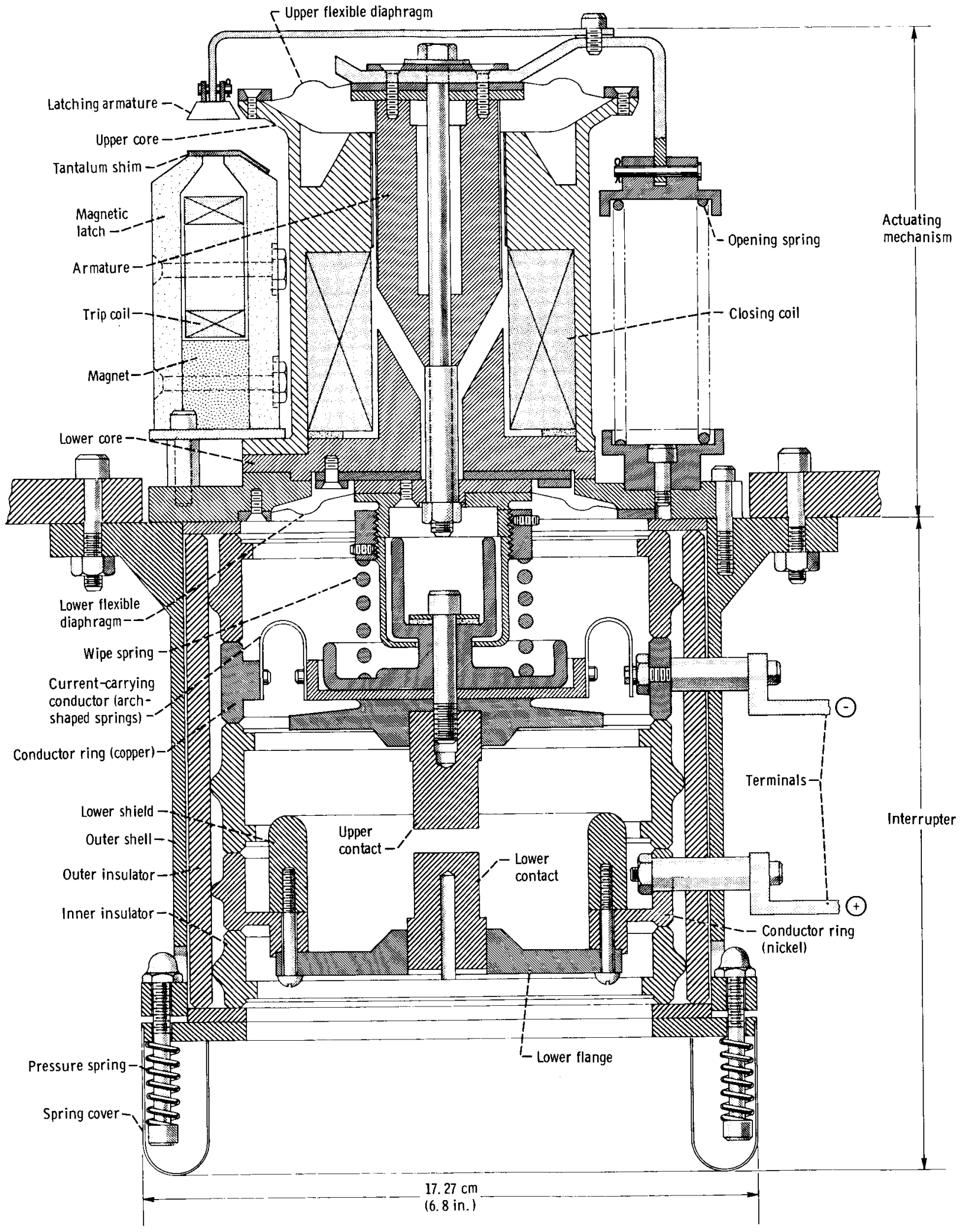

Figure 5. - Cross section of direct-current contactor for corona testing. 


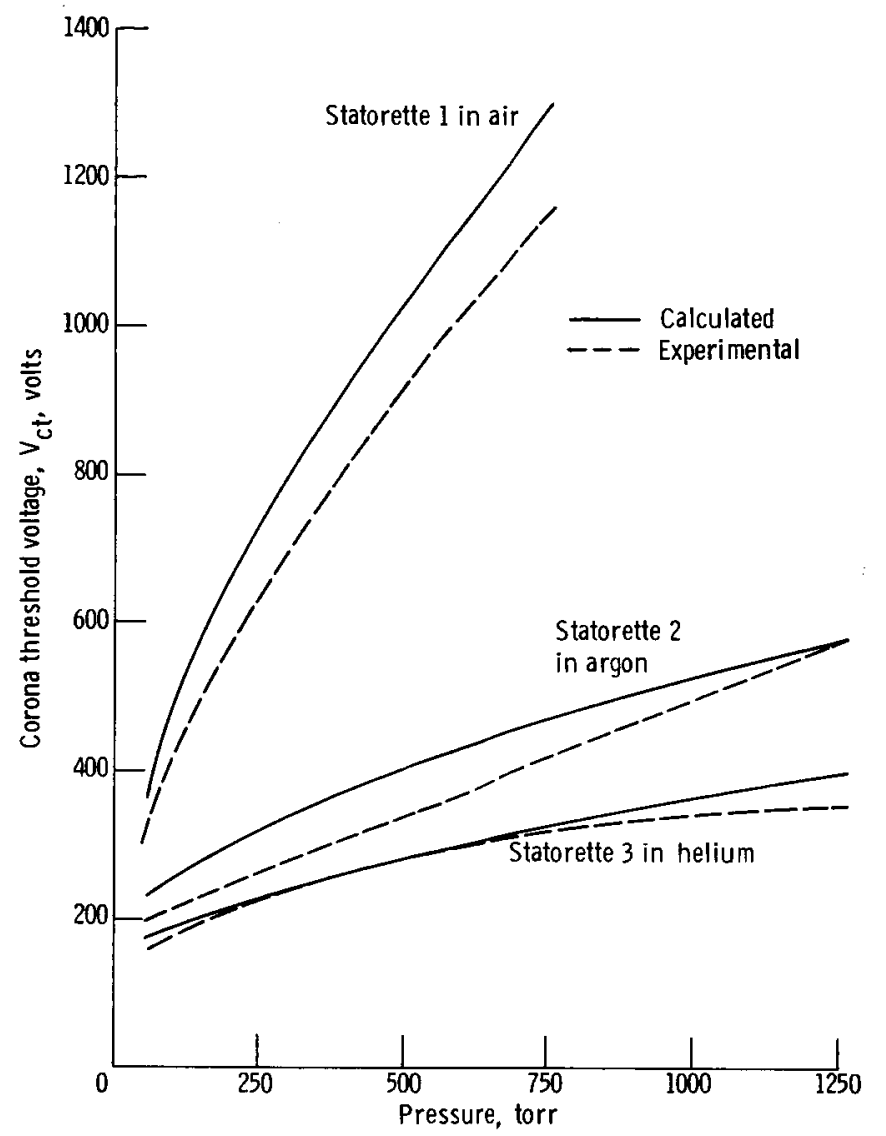

Figure 6. - Corona threshold voltage comparison. 